\title{
Diet-Derived Fatty Acids, Brain Inflammation, and Mental Health
}

\section{OPEN ACCESS}

Edited by:

Rubem C. A. Guedes,

Federal University of Pernambuco,

Brazil

Reviewed by:

Esther Aarts,

Radboud University Nijmegen,

Netherlands

Deborah Clegg,

Cedars-Sinai Medical Center,

United States

*Correspondence:

Sergio T. Ferreira

ferreira@bioqmed.ufrj.br

† Joint first authors

Specialty section:

This article was submitted to Neuroenergetics, Nutrition and Brain

Health,

a section of the journal

Frontiers in Neuroscience

Received: 29 November 2018

Accepted: 06 March 2019

Published: 26 March 2019

Citation:

Melo HM, Santos LE and

Ferreira ST (2019) Diet-Derived Fatty

Acids, Brain Inflammation, and Mental

Health. Front. Neurosci. 13:265.

doi: 10.3389/fnins.2019.00265

\author{
Helen M. Melo ${ }^{1 t}$, Luís Eduardo Santos ${ }^{1,2 t}$ and Sergio T. Ferreira ${ }^{1,2 *}$ \\ ${ }^{1}$ Institute of Medical Biochemistry Leopoldo de Meis, Federal University of Rio de Janeiro, Rio de Janeiro, Brazil, ${ }^{2}$ Institute \\ of Biophysics Carlos Chagas Filho, Federal University of Rio de Janeiro, Rio de Janeiro, Brazil
}

Western societies experienced drastic changes in eating habits during the past century. The modern nutritional profile, typically rich in saturated fats and refined sugars, is recognized as a major contributing factor, along with reduced physical activity, to the current epidemics of metabolic disorders, notably obesity and diabetes. Alongside these conditions, recent years have witnessed a gradual and significant increase in prevalence of brain diseases, particularly mood disorders. While substantial clinical/epidemiological evidence supports a correlation between metabolic and neuropsychiatric disorders, the mechanisms of pathogenesis in the latter are often multifactorial and causal links have been hard to establish. Neuroinflammation stands out as a hallmark feature of brain disorders that may be linked to peripheral metabolic dyshomeostasis caused by an unhealthy diet. Dietary fatty acids are of particular interest, as they may play a dual role, both as a component of high-calorie obesogenic diets and as signaling molecules involved in inflammatory responses. Here, we review current literature connecting dietrelated nutritional imbalance and neuropsychiatric disorders, focusing on the role of dietary fatty acids as signaling molecules directly relevant to inflammatory processes and to neuronal function.

Keywords: fatty acids, high-fat diet, Western diet, mood disorders, neuroinflammation

\section{INTRODUCTION}

Western society experienced a marked nutritional transition during the past century. Multiple factors, stemming primarily from the industrial revolution and mass urbanization, have driven the nutritional profile of the population toward increased consumption of processed and animalderived foods, saturated fats and refined sugars, while reducing the intake of vegetables, fruits, fibers, and fish (Popkin and Gordon-Larsen, 2004; Popkin et al., 2012). Moreover, these altered eating habits have been associated with larger portion sizes and reduced energy expenditure, making modern lifestyle highly obesogenic (Bray and Popkin, 1998; Hill and Peters, 1998; Kopelman, 2000; Berthoud, 2012). During the same time span, the prevalence of mood disorders has increased significantly in Western countries, even when accounting for evolving diagnostic criteria and other confounding factors (Hagnell, 1989; Hidaka, 2012). As mechanisms linking diet to mental health become better understood, accumulating evidence suggests that the modern/Western diet may be one of the drivers of this increase (Jacka et al., 2010; O'Neil et al., 2014).

To address this link, the nascent field of "nutritional psychiatry" (Logan and Jacka, 2014) focuses on clinical studies examining the impact of both isolated nutrients and overall quality of diets on the incidence and progression of prevalent psychiatric conditions, most often anxiety and 
mood disorders. In parallel, the field strives to overcome challenges associated with the combined complexities of human diet and behavior, both of which are difficult to control and evaluate consistently (Jacka, 2017).

Although it is not disputed that the modern lifestyle and nutritional behavior promote a surplus of energy and its storage in the form of expanding adipose tissue (Spiegelman and Flier, 2001), the exact relevance of macronutrient compositionthe balance of protein, carbohydrate and fat-to body weight regulation remains under discussion. While some authors argue for a disproportionate contribution of a single type of nutrient to the development of obesity and metabolic disorders, others sustain that such pathologies are not significantly dependent on diet composition, resting instead squarely on a positive energy balance.

Bray and Popkin (2014), for instance, have suggested that increased intake of carbohydrates-mainly in the form of glucose/fructose-sweetened beverages, a primary source of added sugars in modern society-is a key driver of the modern pandemic of obesity and metabolic conditions (Bray et al., 2004; Bray and Popkin, 2014). Indeed, numerous meta-analyses show a positive correlation between sugar consumption and increased risk of insulin resistance, non-alcoholic fatty liver disease (NAFLD), obesity and type 2 diabetes (Ludwig et al., 2001; Bray et al., 2004; Malik et al., 2006, 2010; Montonen et al., 2007; Ouyang et al., 2008; Bray and Popkin, 2014; Mosca et al., 2017). Although such correlations have not been consistently demonstrated when total energy intake is controlled, authors argue that added calories obtained from sugar-sweetened beverages tend to not be compensated elsewhere, as they do not effectively suppress intake of other calories. Mechanistically, increased fructose uptake and metabolism in the liver stimulates de novo lipogenesis (DNL), which results in increased intrahepatic lipid content, leading to increased production and secretion of very low-density lipoprotein and triglycerides. In the long term, these alterations may result in increased fat storage in visceral adipose tissue and ectopic lipid deposition in tissues such as muscle, further contributing to insulin resistance (Lê et al., 2009; Stanhope et al., 2009; Stanhope, 2016; Mock et al., 2017).

On the other hand, as highlighted by Khan and Sievenpiper (2016), more recent trends of reduced sugar intake by United States adults have not been accompanied by a reduction in obesity and metabolic disorders. In addition, as mentioned above, most controlled trials using isocaloric diets have not shown a specific contribution of any type of nutrient to obesity, suggesting total energy content is the most relevant variable (Kahn and Sievenpiper, 2014; Khan and Sievenpiper, 2016).

Regarding the role of fat intake, Hu et al. (2018) recently published a compelling report comparing the long-term effects of 29 types of diet, with varying proportions of fat, carbohydrates and protein, on five different mouse strains. Surprisingly, they found fat content in a diet to be the only factor involved in increased energy intake and adiposity. This observation was explained by a hedonic drive linked to fat, but they did not observe a similar effect with sugar ( $\mathrm{Hu}$ et al., 2018). The fact that a certain diet composition may drive higher energy intake independent of the diet's own energy density adds an additional layer of complexity to the field, particularly in the design and execution of clinical trials.

$\mathrm{Hu}$ et al. (2018) present an interesting discussion on the translatability of this finding, and the feasibility of performing an equivalent study in humans. However, be it due to its higher energy content compared to other nutrients, to its reward value that drives increased caloric intake, or to specific but not yet fully understood signaling and metabolic dysregulation, the impact of increased fat consumption on the development of diet-related diseases has been well documented over the years (for an excellent recent review, see Ludwig et al., 2018). Although controversy remains on the relevance of total fat intake toward body fat accumulation, with several studies indicating no causal relationship (Curb and Marcus, 1991; Willett, 1998, 2002; Vergnaud et al., 2013), excessive energy intake from dietary fat is established as an important factor to increased adiposity (Horton et al., 1995; Bray and Popkin, 1998).

The fantastic remodeling capacity of adipose tissue allows for adipocyte hypertrophy and hyperplasia in response to nutrient availability and energy surplus. However, under pathological conditions, the need for adaptation exceeds the capacity of the tissue. Hypoxia and adipocyte cell death result in macrophage recruitment and polarization, increasing inflammatory markers, cytokine and chemokine secretion, and dysregulation in free fatty acid (FFA) fluxes (Sun et al., 2011).

Increased circulating FFAs and proinflammatory factors are also central to insulin resistance and deregulation of glucose homeostasis, the core aspects of type 2 diabetes mellitus (T2DM) (Greenberg and Obin, 2006). Obesity and T2DM currently affect a large portion of the world population and are considered a global epidemics, with obesity as the leading risk factor for T2DM (Barnes, 2011).

Notably, the fatty acid composition of diets has been shown to impact their obesogenic profile and overall toxicity. Particularly, enrichment in saturated fatty acids (SFAs) results in a diet that induces greater accumulation of body fat and lower satiety than diets enriched in polyunsaturated fatty acids (PUFAs) (Lawton et al., 2000; Piers et al., 2003; Moussavi et al., 2008; Phillips et al., 2012). Moreover, excessive SFA consumption was shown to increase SFAs in the circulation, increase expression of genes involved in inflammatory processes in adipose tissue, reduce insulin sensitivity and increase intrahepatic triglyceride content in humans (Vessby et al., 2001; van Dijk et al., 2009; Rosqvist et al., 2014).

Long-term longitudinal studies have linked a low intake of PUFAs and high intake of cholesterol and SFAs to increased risk of impaired cognitive function and development of dementia, including Alzheimer's disease (Kalmijn et al., 1997; Morris et al., 2003a,b, 2004; Barnard et al., 2014; Reichelt et al., 2017). In this context, it has been suggested that metabolic imbalance caused by high-fat diets and a sedentary lifestyle constitutes an important AD risk factor, particularly due to its association with higher levels of plasma FFAs, chronic low grade inflammation, insulin resistance and T2DM (De Felice, 2013). Further, whereas moderate intake of PUFAs at midlife appears to decrease the risk of dementia in aging (Laitinen et al., 2006), saturated and transunsaturated fat consumption have been found to be positively 
associated with increased risk of $\mathrm{AD}$ (Morris et al., 2003b). Adherence to a Mediterranean diet and frequent consumption of fruits and vegetables, fish, and $\omega-3$ (n-3 PUFA) rich oils has been proposed as a factor capable of preventing $\mathrm{AD}$ and dementia (Scarmeas et al., 2006; Barberger-Gateau et al., 2007, 2011). Moreover, cognitive performance in elderly people (6590 years old), free from significant cognitive impairment, was better in subjects having high intakes of vegetables, fruits, and vitamins and lower intakes of monounsaturated fatty acids, SFAs, and cholesterol (Ortega et al., 1997).

A close relationship exists between metabolic syndrome, T2DM and brain dysfunction, encompassing both mood and cognitive disorders (Ott et al., 1996; De Felice, 2013; Santos et al., 2016; Rebolledo-Solleiro et al., 2017). The mechanisms underlying this connection appear largely based on neuroinflammation and dysregulated brain insulin signaling, both of which can result from nutritional imbalance (reviewed in Luchsinger, 2012; De Felice and Ferreira, 2014; Holt et al., 2014; Sevilla-González et al., 2017).

In the following sections, we focus on data available on the connection between dietary fatty acids and their potential role in mental health, particularly in depressive disorders. We explore how, due to their potential as modulators of neuroinflammation and insulin signaling, fatty acids may be key to the interplay between diet and mental health. We also discuss some of the more recent work exploring how the dopaminergic system, increasingly implicated in the pathophysiology of depression, may be affected by dietary choices.

\section{HUMAN POPULATIONAL STUDIES}

While numerous observational studies have been carried out, randomized controlled trials (RCTs) on the relationship between diet and mood disorders are comparatively rare. A meta-analysis conducted in 2014 (Lai et al., 2014) examined links between dietary patterns and depression, and found 20 observational studies meeting inclusion criteria, but only one RCT. These authors concluded that 'healthy' diets, including a high intake of fruit, vegetables, fish and whole grains, were inversely correlated with depression. Around the same time, another metaanalysis carried out by Psaltopoulou et al. (2013) reached similar conclusions while examining nine observational studies that had depression as the main outcome and eight studies evaluating cognitive function. They found a significant association between adherence to the Mediterranean diet - a diet pattern similar to what Lai et al. (2014) classified as healthy - and lower rates of both depression and cognitive impairment.

Since humans do not typically consume any single type of food in isolation, studies with isolated nutrients, such as fatty acids, are not only difficult to perform, but also trade potential relevance for increased power. Thus, to approach questions dealing with the roles of specific nutrients, authors often rely on supplementation or on observational studies to seek correlations between study outcomes and specific biomarkers reflecting a nutrient's level of intake or metabolism. Interestingly, a meta-analysis of 13 randomized placebo-controlled trials enrolling a total of 1,233 patients with major depressive disorder (MDD) demonstrated a beneficial effect of omega-3 PUFA supplementation on depressive symptoms (Mocking et al., 2016), with a larger effect at higher doses and in patients being simultaneously treated with antidepressants, suggesting a potential adjuvant role of omega-3 fatty acids in MDD treatment.

Results from several other meta-analyses and epidemiological studies suggest that reduced levels of PUFAs could be involved in the pathogenesis of cognitive and mood disorders, and may be therapeutic targets in those diseases. A meta-analysis of 14 studies found that subjects with depressive symptoms or social anxiety disorders had lower circulating levels of the n-3 PUFAs, eicosapentaenoic acid, 20:5n-3 (EPA) and docosahexaenoic acid, 22:6n-3 (DHA), and/or higher levels of the n-6 PUFA, arachidonic acid, 20:4n-6 (ARA), than control subjects (Lin et al., 2010). In addition, post-mortem analysis of orbitofrontal and prefrontal cortex of patients with major depression showed lower DHA levels compared to controls (McNamara et al., 2007, 2013). Moreover, a recent 7-year follow-up study of 69 young individuals with an ultra-high risk phenotype for psychosis demonstrated that lower levels of EPA and/or DHA, and higher n-6/n-3 PUFA ratio in the phosphatidylethanolamine fraction of erythrocyte membranes, specifically predicted mood disorders (in this cohort, 24 patients received a diagnosis of MDD and 2 of bipolar disorder during the follow-up period; Berger et al., 2017). Altogether, these and other studies implicate PUFAs in the pathogenesis of mood and cognitive disorders, providing a basis for nutritional psychiatry approaches in these highly prevalent and incapacitating diseases.

\section{HIGH-FAT DIET IN RODENT MODELS}

Many of the current inferences on the impact of HFD on human health have been based on or influenced by studies in animal models, mostly rodents. As in humans, fat-enriched diets induce rapid weight gain and metabolic alterations in animal models. Although the term 'high-fat diet' is widely used to describe studies in which fat corresponds to the highest proportion of energy intake, that percentage may range from 20 to $60 \%$ of total energy intake and diet composition may include animal-derived fats or plant oils. Moreover, the composition of the control diet is often not standardized, with non-purified chow being used as a control and some studies omitting to mention the composition of the control diet altogether (Buettner et al., 2007; Hariri and Thibault, 2010). Further, the age at which exposure to HFD is initiated is also variable among studies. Lack of standardization in studies under the HFD umbrella leads to great variability in observed outcomes and difficulty in establishing comparisons between studies.

Despite the different protocols, some of the effects of excess fat in the diet appear to be central and robust in mice. In a landmark report by Xu et al. (2003), for instance, obesity induced in C57BL/6J mice by long-term exposure to a HFD (containing up to $60 \%$ calories from fat) produced increases in adipocyte number and size, body weight, fasting blood glucose levels, and induced hyperinsulinemia (Xu et al., 2003). Those metabolic 
changes were later shown to occur even after a short period of fat-enriched diet consumption (Lee et al., 2011).

Hotamisligil et al. (1993) demonstrated a central role of TNF$\alpha$ in diabetes and obesity-induced insulin resistance, using $\mathrm{db} / \mathrm{db}$, $\mathrm{ob} / \mathrm{ob}$, tub/tub, and fa/fa mice, genetic models of metabolic disorders (recently reviewed in Kleinert et al., 2018). In those mice, Hotamisligil et al. (1993) showed that increased expression of TNF- $\alpha$ in adipocytes as well as high levels of this cytokine in the circulation resulted in insulin resistance. In line with those findings, $\mathrm{Xu}$ et al. (2003) went on to show that excessive macrophage recruitment and upregulated expression of ADAM8, MIP-1 $\alpha$, MCP-1, MAC-1, F4/80, and CD68 in white adipose tissue contribute to the establishment of chronic inflammation and increased production and release of pro-inflammatory cytokines, notably TNF- $\alpha$ and IL-6, into the circulation. These results were later corroborated by others, and positioned obesityinduced inflammation into a broader picture (Hotamisligil et al., 1993; Wellen and Hotamisligil, 2003; Xu et al., 2003; Lumeng et al., 2007; Eder et al., 2009).

The HFD mouse model has been instrumental in dissecting the molecular mechanisms involved in FFA-induced T2DM. It was first shown in humans that excessive FFAs in the circulation inhibit insulin signaling and glucose metabolism in several tissues, such as adipocytes, liver, and muscle. Excessive FFAs were shown to reduce muscle glucose transport and metabolism via decreased GLUT4 translocation to the plasma membrane (Roden et al., 1996) and to inhibit insulin signaling by increasing IRS-1 serine phosphorylation and reducing insulin-stimulated PI3-kinase activity (Goodyear et al., 1995; Dresner et al., 1999). The important role of inflammatory responses in this process, which culminate in the activation of stress kinases such as JNK and IKK $\beta$, which in turn target IRS, was described in HFD mouse models (Yuan et al., 2001; Hirosumi et al., 2002; Arkan et al., 2005).

Increased saturated FFAs, observed in obesity and high fat intake models, have an intrinsic pro-inflammatory potential that impacts important cell functions. Fatty acids may activate Tolllike receptor 4 (TLR4) signaling in adipocytes and macrophages and induce inflammatory signaling (Shi et al., 2006), and mice lacking TLR4 were shown to be protected against highfat diet-induced obesity and insulin resistance (Poggi et al., 2007; Davis et al., 2008). TLRs are a family of type I transmembrane receptors that recognize a variety of microbial danger-associated molecular patterns (DAMPs) and pathogenassociated molecular patterns (PAMPs) and orchestrate an intracellular signaling response, playing an important role in infectious and inflammatory disorders. Amongst at least 13 members of TLRs described in mammals, TLR2 and TLR4 are best characterized in terms of their involvement in the immune response (Fessler et al., 2009). TLR4 plays a critical role in the innate immune system by activating MyD88-dependent and MyD88-independent proinflammatory signaling pathways, as well as the NFKB response (Lu et al., 2008).

Mood disorders cannot be fully reproduced in rodent models. In addition to their incompletely understood etiology, they involve symptoms that may not exist outside of the human experience, such as inappropriate guilt and suicidality
(Krishnan and Nestler, 2011). However, rodent models may exhibit depressive-like symptoms, such as behavioral correlates of hopelessness or anhedonia. Recent data on rats and mice fed HFD suggest a positive association between HFD and such depressed phenotypes (Yang et al., 2016; Arcego et al., 2018; Hassan et al., 2018), which may be causally linked to diet-induced inflammatory processes, as discussed below.

\section{SATURATED FATTY ACIDS AND NEUROINFLAMMATION: POSSIBLE LINKS TO MOOD DISORDERS}

Microglial cells respond rapidly to pathological changes in the brain, altering their morphology and phagocytic behavior, and increasing cytotoxic responses by secreting $\mathrm{NO}$, proteases and cytokines, such as TNF- $\alpha$ and IL-1 $\beta$ (Kreutzberg, 1996). SFAs, such as palmitic acid, have been shown to induce activation of TLR4 receptors in hypothalamic microglia and to stimulate cytokine release (Valdearcos et al., 2014), indicating a potential mechanism by which HFD leads to brain inflammation. Notably, the hippocampus - a key brain region involved not only in learning and memory but also in depression and the effect of antidepressants-is vulnerable to altered levels of IL- $1 \beta$, IL-6, and TNF- $\alpha$, as these cytokines have important roles in synaptic plasticity and may inhibit neurogenesis (Sheline, 2011; Calabrese et al., 2014).

Microglia and astrocytes are essential to normal synaptic function. Synaptic pruning by microglia is essential to synaptic maturation and neurotransmission (Paolicelli et al., 2011), while astrocytes hold important metabolic and plasticity functions (Beattie et al., 2002; Singh and Abraham, 2017). Importantly, HFD-induced depressive-like behavior in rodents, as well as cognitive impairment, has been associated with brain inflammation. For instance, Dutheil et al. (2016) showed that, in addition to the classical metabolic alterations, rats fed an HFD (60\% of calories as fat) for 16 weeks show anhedonic behavior, which presents alongside insulin signaling impairment and increased levels of cytokines such as IL-6, IL-1 $\beta$, and TNF$\alpha$ in the hippocampus. In turn, mice exposed to long term HFD were shown to have spatial memory deficits in the Morris water maze, with increased serum and hippocampal levels of TNF- $\alpha$ and presence of activated microglia in the hippocampus, as well as reduced dendritic branching and complexity (Heyward et al., 2012; Jeon et al., 2012).

In line with the structural similarity between SFAs and the lipid portion of bacterial lipopolysaccharide (LPS), several lines of evidence suggest that SFAs act as ligands of TLRs. In vitro experiments have shown that SFAs activate TLR2 to induce an inflammatory response (Erridge and Samani, 2009; Huang et al., 2012), and numerous reports have linked SFAs to TLR4-mediated signaling pathways in immune cells (Park et al., 2009; Rogero and Calder, 2018). Using both the BV-2 microglial cell line and primary microglial cultures, Wang et al. (2012) demonstrated that palmitic acid and stearic acid induce a reactive microglial phenotype and increase levels of inflammatory markers in a TLR4-dependent manner. The SFAs, lauric, palmitic, and stearic 
acids, but not unsaturated fatty acids or PUFAs, were shown to induce NF- $\kappa \mathrm{B}$ activation and expression of COX-2 and other inflammatory markers in macrophages, effects inhibited in dominant-negative TLR4 cells (Lee et al., 2001). Further, the liver secretory protein fetuin-A (FetA) has been suggested as an adaptor protein between FFAs and TLR4 activation, connecting FFAs to TLR-mediated inflammation (Pal et al., 2012). Importantly, however, the role of TLRs as SFA receptors is still a matter of debate. The most recent challenge to this notion was a compelling report by Lancaster et al. (2018) suggesting that SFAs are not direct ligands of TLR4 in macrophages, but instead contribute to pro-inflammatory signaling by altering lipid metabolism in these cells. They reconcile these results with past literature findings by showing that, despite not being a direct target, TLR4-dependent priming is a requirement for SFA-induced inflammatory signaling.

Inflammation has emerged as an important factor in mood disorders. Patients presenting mood disorders show elevated plasma levels of cytokines such as TNF- $\alpha$, IL-6, and IL- $1 \beta$, as well as increased expression of inflammatory markers in blood cells (reviewed by Mechawar and Savitz, 2016). Increased consumption of high fat diet is related to depressive-like behavior and emotional disorders in mice (Wang et al., 2017; Arcego et al., 2018; Vagena et al., 2018; Xu et al., 2018), and neuroinflammation could be an important modulator of these behavioral alterations. Palmitic acid abolished the migration and phagocytic activity of microglia in response to interferon- $\gamma$, thus affecting the protective response of these cells after an inflammatory challenge in vitro (Yanguas-Casás et al., 2018). Post-mortem analysis of brain tissue from MDD patients indicated a $6.5 \%$ increase in palmitic acid and a $6.2 \%$ decrease in oleic acid in the amygdala, as compared to controls (Hamazaki et al., 2012), further suggesting that altered levels of specific fatty acids may be implicated in brain dysfunction.

One potential mechanistic connection between neuroinflammation and mood disorders is the positive effect of pro-inflammatory cytokines on microglial expression of indolamine-2,3-dioxygenase (IDO), the enzyme that converts tryptophan to kynurenine (Wichers and Maes, 2004; Dantzer et al., 2008). Lower availability of tryptophan in the brain due to upregulation of this alternative pathway could slow down its conversion to 5-hydroxytryptophan, the rate-limiting step in serotonin synthesis, carried out by tryptophan hydroxylase. Notably, while far from the only factor involved, serotonin depletion has been shown to induce depressive-like symptoms in animal models and impact mood in humans under certain conditions (Ruhé et al., 2007; O’Connor et al., 2009). Furthermore, increased kynurenine metabolism may result in excessive production of 3-hydroxykynurenine, a generator of reactive oxygen species (ROS), and quinolinic acid, an NMDA receptor agonist, both of which could have their own implications to depression (Müller and Schwarz, 2007).

Another possible mechanism linking neuroinflammation to mood involves precisely the vulnerability of monoaminergic pathways to oxidative stress. Tetrahydrobiopterin $\left(\mathrm{BH}_{4}\right)$ is an essential cofactor, required for certain enzymatic reactions such as those carried out by tryptophan hydroxylase, phenylalanine hydroxylase (which coverts phenylalanine to tyrosine) and tyrosine hydroxylase (which converts tyrosine to L-DOPA, the rate limiting step in dopamine synthesis). $\mathrm{BH}_{4}$ may be readily inactivated by ROS, a likely event in strong proinflammatory contexts, thus affecting dopamine and serotonin levels (reviewed by Swardfager et al., 2016). Notably, in addition to the role of serotonin mentioned above, recent reports have shown that dopamine neurotransmission, particularly in the ventral tegmental area-nucleus accumbens circuit, is essential for the expression of depressed phenotypes and social behavior, and thus its depletion could contribute to mood disorders (Tye et al., 2012; Gunaydin et al., 2014; Matthews et al., 2016).

\section{POLYUNSATURATED FATTY ACIDS, NEUROINFLAMMATION AND LINKS TO MOOD DISORDERS}

The nutritional transition observed worldwide in the past few decades has introduced high amounts of SFAs and omega-6 (n-6) PUFAs in the human diet through increased intake of dairy products, vegetable oils and red meat. This change in dietary profile was further accompanied by a reduction in consumption of fruits, vegetables, legumes, grains and fish, important sources of omega-3 (n-3) PUFAs. These changes resulted in an increase in omega-6/omega-3 ratio from about 1:1 to 10:1, reaching up to 2025:1 or higher, and an alarming omega-3 deficiency in the global population, mainly in Western countries (Simopoulos, 2011).

Omega-3 and omega-6 PUFAs are categorized in these two groups according to the position of the double bond closest to the methyl terminus of the hydrocarbon chain, and, together, comprise the very-long chain family of polyunsaturated fatty acids (VLC-PUFAs). The main VLC-PUFAs in humans are the omega-3 PUFAs, EPA and DHA, and the omega-6 PUFA, ARA, which are components of membrane phospholipids and important signaling molecules (Zárate et al., 2017). In humans, VLC-PUFAs are endogenously synthesized in small amounts from dietary intake of the essential fatty acids, linoleic acid (LA) and alpha-linolenic acid (ALA). These are precursors of ARA, EPA, and DHA synthesis through the action of elongase and desaturase enzymes, which successively elongate and include double bonds into the carbon chain. Thus, adequate balance of these nutrients in the diet is necessary for healthy development, survival and aging (Calder, 2018).

The brain is a lipid-rich organ, and approximately $35 \%$ of those lipids are PUFAs (Yehuda et al., 1999). DHA and ARA are major PUFA components in brain cells. They are predominantly found esterified as glycerophospholipids at the plasma membrane (approximately 10,000 nmol per gram of brain tissue) but are also found at much lower amounts in non-esterified form (about $1 \mathrm{nmol}$ per gram of brain tissue). They act as structural components and signaling molecules in neurons, glial cells, and endothelial cells (Bazinet and Layé, 2014). Studies in humans and, mainly, in animal models have revealed that PUFAs enter the brain via lipoproteins or albumin transport in esterified form, as lysophosphatidylcholine, or in non-esterified form, 
by passive diffusion through a flip-flop mechanism or through protein transporters, such as fatty acid binding proteins (FABPs), fatty acid transport protein (FATP), fatty acid translocases (FAT/CD36) and major facilitator superfamily domaincontaining protein 2 (Mfsd2a) (Lauritzen et al., 2001; Umhau et al., 2009; Domenichiello et al., 2014; Nguyen et al., 2014; Chen et al., 2015; Liu et al., 2015; Pan et al., 2015, 2016; Hachem et al., 2016). PUFAs play important roles in brain function, including synaptic plasticity, neurotransmission, metabolism, neurogenesis, neuroinflammation and neuroprotection (Bazinet and Layé, 2014). Not surprisingly, therefore, reduced or unbalanced dietary supply and brain levels of PUFAs (notably, DHA) are associated with brain disorders, including cognitive and mood disorders (see below).

In addition to modulation of serotonin (5-HT1 and 5-HT4), beta-adrenergic and dopamine (D1 and D2) receptor signaling through increased adenylate cyclase and protein kinase A (PKA) activities (Liu et al., 2015), PUFAs play an important role in neuroinflammation, an important etiologic factor of mood disorders (Chang et al., 2015; Yirmiya et al., 2015; Chen et al., 2018). Omega-6 and omega-3 PUFAs have opposite effects on inflammatory modulation. ARA is an important precursor of eicosanoids, bioactive molecules that regulate the inflammatory process in immune cells. In response to inflammatory stimuli, membrane phospholipids are cleaved by phospholipase A2 (PLA-2) and release ARA, a substrate of cyclooxygenase (COX), lipoxygenase (LOX) and cytochrome P450. This stimulates synthesis of prostaglandins (PGs), thromboxanes (TXs), and leukotrienes (LTs), key pro-inflammatory mediators (Innes and Calder, 2018). Post-mortem analysis of brains from patients with bipolar disorders indicated a dysregulation of ARA release and downstream metabolism in frontal cortex (Kim et al., 2009), and mood stabilizers such as lithium, valproate and carbamazepine have been found to modify the ARA cascade in the brain (Kim et al., 2009). These findings suggest that increased levels of ARA from the diet could lead to exacerbation and dysregulation of the inflammatory response in brain cells, thus contributing to mechanisms associated with mood disorders.

In vitro studies showed that omega-3 PUFAs modulate microglial functions. For instance, EPA treatment inhibited microglial production of proinflammatory cytokines (IL-1 $\beta$, IL6 , and TNF- $\alpha$ ) (Liuzzi et al., 2007) in vitro, and supplementation with omega-3 PUFAs inhibited microglial activation and shifted microglial profile from the so-called classical pro-inflammatory M1 to the neuroprotective M2 phenotype in a model of brain injury in rats (Chen et al., 2018). When incorporated into microglial membranes, DHA, which has been described as a potent immunomodulator in brain cells (Antonietta AjmoneCat et al., 2012), blocked the recognition of LPS by cell surface receptors and inhibited nuclear factor kappa B (NF$\kappa B)$ activation and synthesis of IL- $1 \beta$ and TNF- $\alpha$ (De SmedtPeyrusse et al., 2008). In addition, DHA prevented LPSinduced neuroinflammation and restored synaptic structure and functions in hippocampal CA1 pyramidal neurons (Chang et al., 2015). In Fat-1 mice, which convert n-6 to n-3 PUFAs in the brain, feeding with a DHA-enriched diet prevented LPSinduced increases in pro-inflammatory cytokines, microglial activation, depressive-like behavior and reduction in BDNF levels (Gu et al., 2018).

Omega-3 PUFAs, mainly EPA, are competitive substrates for enzymes involved in the biosynthesis of inflammatory mediators derived from ARA. Increased PUFA consumption results in a membrane phospholipid composition with increased levels of these fatty acids, and in a reduction of ARA-derived inflammatory mediators (reviewed in Calder, 2015). Moreover, DHA and EPA are precursors of important lipid mediators with anti-inflammatory and pro-resolutive actions, such as resolvins and protectins. Resolvin D1 (RvD1) and resolvin E1 (RvE1), for example, decrease LPS-induced microglial expression of proinflammatory cytokines, namely TNF- $\alpha$, IL-6, and IL- $1 \beta$ (Rey et al., 2016).

\section{FATTY ACIDS, MICROBIOTA CHANGES, AND MOOD DISORDERS}

Recently, the gut-microbiota-brain axis has been implicated in neuroinflammation and the development of neuropsychiatric disorders. A comparative analysis between children from a rural African village in Burkina Faso (fed a rural diet) and European children (fed a modern Western diet) indicated significant differences in gut microbiota between the two groups (De Filippo et al., 2010), and suggested an important role of the nutritional transition in altering the human gut microbiome and in the development of inflammatory diseases.

The gut microbiome rapidly responds to dietary composition. Using mouse models, David et al. showed that short-term exposure to diets enriched in animal or plant products changed microbiota composition and microbial gene expression (David et al., 2014). Feeding a HFD caused shifts in the gut bacterial ecosystem in mice (Daniel et al., 2014). More recently, mice fed a HFD for 8 weeks were shown to present a depressive-like phenotype accompanied by a relative reduction in the population of Bacteroidetes and increase in the population of Firmicutes and Cyanobacteria in their caecal microbiome (Hassan et al., 2018). Interestingly, MDD patients showed different abundances of Firmicutes, Actinobacteria and Bacteroidetes when compared to healthy controls. In the same study, transplantation of fecal microbiota from MDD patients into mice resulted in depressivelike behaviors compared with colonization with microbiota derived from healthy control individuals (Zheng et al., 2016). Similarly, transplantation of fecal microbiota from depressed patients to microbiota-depleted rats induced anhedonia and anxiety-like behaviors (Kelly et al., 2016).

The detailed mechanisms underlying how changes in microbiota may lead to mood disorders remain unclear, but neuroinflammation appears as a potential mechanism. Microglia from germ-free mice showed decreased expression of genes associated with inflammation and defense responses, and an immature profile when compared with microglia from control mice (Matcovitch-Natan et al., 2016; Fung et al., 2017). Moreover, microbiota complexity has a central role in microglia function, regulating the neuroinflammatory response in health and disease (Erny et al., 2015). 


\section{ADIPONECTIN}

Adiponectin, a hormone released by adipocytes and found abundantly in plasma and at lower concentrations in the CSF (Ebinuma et al., 2007), has been linked to mood disorders, and may connect dietary changes to behavior, particularly with respect to long-term effects. Circulating levels of adiponectin and the response elicited by activation of its receptors, AdipoR1 and AdipoR2 (found in several organs, including the brain), have been shown to be modulated by inflammatory and metabolic conditions, such as obesity and diabetes (Hotta et al., 2000; Yang et al., 2002). Although consistent human data are lacking, adiponectin has anti-depressant (Liu et al., 2012) and antiinflammatory (Ouchi and Walsh, 2007) properties in mice. It has also been shown to be a candidate mediator of the positive effects of exercise and environmental enrichment on neurogenesis, mood, and cognition (Chabry et al., 2015).

\section{THE INSULIN-DOPAMINE LINK}

Kleinridders et al. (2015) showed that reduced insulin signaling in the brain, as a result of insulin resistance, led to increased levels of monoamine oxidases and increased dopamine clearance. They further showed that this change in dopamine metabolism led to age-related anxiety and depressive-like behavior in mice, results consistent with the above mentioned increasingly important role of dopamine signaling in mood disorders.

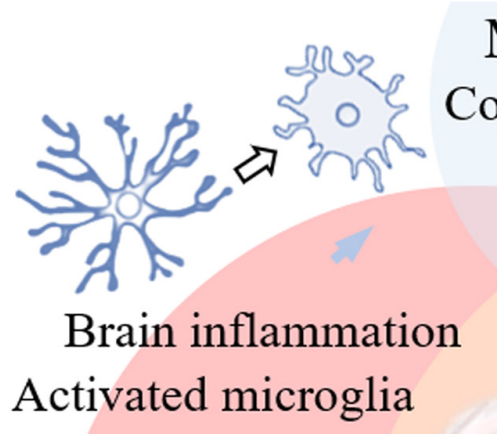

\section{Mood disorders} Cognitive impairment
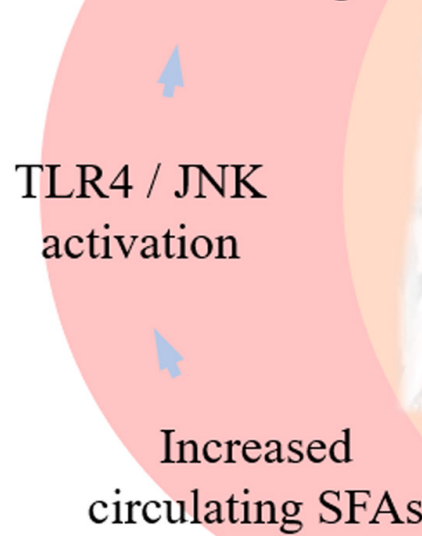

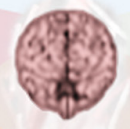

\section{Dopaminergic dysfunction}

\author{
Peripheral / brain \\ insulin resistance
}

Changes in the gut microbiome

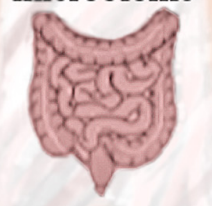

Peripheral cytokine release

Adiposity

Modern diet

4 SFAs

$\downarrow$ PUFAs

FIGURE 1 | Pathways linking diet and mental health. The nutritional transition observed in modern society, mainly in Western countries, has resulted in increased consumption of SFAs and reduced intake of PUFAs. Excessive energy intake from fat-enriched diets increases fatty acid storage and surpasses the remodeling capacity of adipose tissue, resulting in macrophage recruitment and increasing circulating levels of proinflammatory cytokines. Increased cytokine levels lead to the activation of stress kinases, such as JNK and IKK , resulting in increased IRS-1 serine phosphorylation and reduced insulin-stimulated PI3-kinase activity, causing central and peripheral insulin resistance. Brain inflammation and insulin resistance have been implicated in cognitive deficits (reviewed in De Felice et al., 2014; Ferreira et al., 2014). A recent report further suggested that reduced insulin signaling in the brain affects dopamine metabolism and release, contributing to mood disorders (Cai et al., 2018). Whether this dopaminergic dysfunction is also related to cognitive impairment is a possibility yet unexplored. Excessive energy intake from dietary fat further results in dysregulation of free fatty acid (FFA) fluxes, reducing PUFAs and increasing SFAs in the circulation. Although the exact mechanism is still controversial (Lancaster et al., 2018), several reports have shown that SFAs activate TLR4-dependent signaling pathways that increase inflammatory responses in microglia and induce brain inflammation, another potential mechanism involved in the development of both mood disorders and cognitive impairment. At the same time, dietary choices are known to impact the gut microbiota, which may regulate neuroinflammatory responses. Together, these interconnecting mechanisms suggest relevant links between lipid imbalance associated with fat-enriched diets and the onset and progression of neuropsychiatric and cognitive disorders. 
Complementing their previous results (Kleinridders et al., 2015), the same group later used conditional insulin receptor knockout mice to show that insulin signaling in astrocytes has a role in regulating dopaminergic transmission, via the release of the gliotransmitter ATP (Cai et al., 2018). Their results suggest that activation of insulin receptors in astrocytes activates Munc18c to promote ATP exocitosis, which acts on $\mathrm{P} 2 \mathrm{X}$ receptors on dopaminergic neurons to modulate dopamine release and normal mood behavior. These results also led to the conclusion that dopamine signaling may be altered and contribute to mood disorders in an insulin resistance scenario (Cai et al., 2018).

Moreover, Fordahl and Jones (2017) demonstrated in mice that prolonged consumption of an HFD impairs insulin signaling in the nucleus accumbens and reduces dopamine reuptake in dopaminergic terminals. Notably, restoring insulin signaling could revert this deficit, suggesting that loss of insulin sensitivity may be the cause of altered dopaminergic in the region (Fordahl and Jones, 2017).

\section{PERSPECTIVES AND CONCLUDING REMARKS}

Given the high rate of failure of antidepressant therapies, with at least $30 \%$ of patients being unresponsive to multiple rounds of pharmacological treatment (Sinyor et al., 2010), and the lack of effective, disease modifying treatments for dementia, the prospect of dietary interventions for mood and cognitive disorders is appealing. Notably, the targets involved in potential dietary approaches to mental health may in fact overlap with targets for pharmacotherapy in current clinical trials, including neuroinflammation (e.g., TLR and cytokine receptors) and brain insulin signaling (Figure 1). To reach

\section{REFERENCES}

Antonietta Ajmone-Cat, M., Lavinia Salvatori, M., De Simone, R., Mancini, M., Biagioni, S., Bernardo, A., et al. (2012). Docosahexaenoic acid modulates inflammatory and antineurogenic functions of activated microglial cells. $J$. Neurosci. Res. 90, 575-587. doi: 10.1002/jnr.22783

Arcego, D. M., Toniazzo, A. P., Krolow, R., Lampert, C., Berlitz, C., dos Santos Garcia, E., et al. (2018). Impact of high-fat diet and early stress on depressivelike behavior and hippocampal plasticity in adult male rats. Mol. Neurobiol. 55, 2740-2753. doi: 10.1007/s12035-017-0538-y

Arkan, M. C., Hevener, A. L., Greten, F. R., Maeda, S., Li, Z. W., Long, J. M., et al. (2005). IKK- $\beta$ links inflammation to obesity-induced insulin resistance. Nat. Med. 11, 191-198. doi: 10.1038/nm1185

Barberger-Gateau, P., Raffaitin, C., Letenneur, L., Berr, C., Tzourio, C., Dartigues, J. F., et al. (2007). Dietary patterns and risk of dementia: the Three-City cohort study. Neurology 69, 1921-1930. doi: 10.1212/01.wnl.0000278116.37320.52

Barberger-Gateau, P., Samieri, C., Feart, C., and Plourde, M. (2011). Dietary omega 3 polyunsaturated fatty acids and Alzheimers disease: interaction with apolipoprotein E genotype. Curr. Alzheimer Res. 8, 479-491. doi: 10.2174/ 156720511796391926

Barnard, N. D., Bunner, A. E., and Agarwal, U. (2014). Saturated and trans fats and dementia: a systematic review. Neurobiol. Aging 35, S65-S73. doi: 10.1016/ J.NEUROBIOLAGING.2014.02.030

Barnes, A. S. (2011). The epidemic of obesity and diabetes: trends and treatments. Texas Hear. Inst. J. 38, 142-144. this goal, an important step will be to understand and dissect the distinct but interdependent roles of fatty acids as nutrients and signaling molecules in the brain, and their impact on brain function and dysfunction. Finally, since no food is consumed in isolation by humans, this should happen as part of a larger effort to explore the already proposed potential of other nutrients, particularly carbohydrates, as competing players in both inflammation and insulin signaling (DiNicolantonio et al., 2018).

\section{AUTHOR CONTRIBUTIONS}

All authors discussed and contributed ideas to the manuscript. HM and LS shared most of the writing work. SF advised the process and edited the manuscript.

\section{FUNDING}

Work in the authors' group has been funded by grants from National Institute for Translational Neuroscience (Brazil) and the Brazilian agencies Conselho Nacional de Desenvolvimento Científico e Tecnológico (CNPq), Fundação de Amparo à Pesquisa do Estado do Rio de Janeiro (FAPERJ) and Coordenação de Aperfeiçoamento de Pessoal de Nível Superior (CAPES). LS and HM are recipients of post-doctoral fellowships from CAPES and FAPERJ, respectively.

\section{ACKNOWLEDGMENTS}

Elements of the figure were based on images available on the Mind the Graph platform (www.mindthegraph.com).

Bazinet, R. P., and Layé, S. (2014). Polyunsaturated fatty acids and their metabolites in brain function and disease. Nat. Rev. Neurosci. 15, 771-785. doi: 10.1038/ nrn3820

Beattie, E. C., Stellwagen, D., Morishita, W., Bresnahan, J. C., Ha, B. K., Von Zastrow, M., et al. (2002). Control of synaptic strength by glial TNFalpha. Science 295, 2282-2285. doi: 10.1126/science.1067859

Berger, M. E., Smesny, S., Kim, S. W., Davey, C. G., Rice, S., Sarnyai, Z., et al. (2017). Omega-6 to omega-3 polyunsaturated fatty acid ratio and subsequent mood disorders in young people with at-risk mental states: a 7-year longitudinal study. Transl. Psychiatry 7:e1220. doi: 10.1038/tp.2017.190

Berthoud, H.-R. (2012). The neurobiology of food intake in an obesogenic environment. Proc. Natl. Acad. Sci. U.S.A. 71, 478-487. doi: 10.1017/ S0029665112000602

Bray, G. A., Nielsen, S. J., and Popkin, B. M. (2004). Consumption of high-fructose corn syrup in beverages may play a role in the epidemic of obesity. Am. J. Clin. Nutr. 79, 537-543. doi: 10.1093/ajcn/79.4.537

Bray, G. A., and Popkin, B. M. (1998). Dietary fat intake does affect obesity! Am. J. Clin. Nutr. 68, 1157-1173. doi: 10.1093/ajcn/68.6.1157

Bray, G. A., and Popkin, B. M. (2014). Dietary sugar and body weight: have we reached a crisis in the epidemic of obesity and diabetes: health be damned! Pour on the sugar. Diabetes Care 37, 950-956. doi: 10.2337/dc132085

Buettner, R., Schölmerich, J., and Bollheimer, L. C. (2007). High-fat diets: modeling the metabolic disorders of human obesity in rodents. Obesity 15, 798-808. doi: $10.1038 /$ oby.2007.608 
Cai, W., Xue, C., Sakaguchi, M., Konishi, M., Shirazian, A., Ferris, H. A., et al. (2018). Insulin regulates astrocyte gliotransmission and modulates behavior. J. Clin. Invest. 128, 2914-2926. doi: 10.1172/JCI99366

Calabrese, F., Rossetti, A. C., Racagni, G., Gass, P., Riva, M. A., and Molteni, R. (2014). Brain-derived neurotrophic factor: a bridge between inflammation and neuroplasticity. Front. Cell. Neurosci. 8:430. doi: 10.3389/fncel.2014.00430

Calder, P. C. (2015). Marine omega-3 fatty acids and inflammatory processes: effects, mechanisms and clinical relevance. Biochim. Biophys. Acta 1851, 469-484. doi: 10.1016/j.bbalip.2014.08.010

Calder, P. C. (2018). Very long-chain n-3 fatty acids and human health: fact, fiction and the future. Proc. Nutr. Soc. 77, 52-72. doi: 10.1017/S0029665117003950

Chabry, J., Nicolas, S., Cazareth, J., Murris, E., Guyon, A., Glaichenhaus, N., et al. (2015). Enriched environment decreases microglia and brain macrophages inflammatory phenotypes through adiponectin-dependent mechanisms: relevance to depressive-like behavior. Brain Behav. Immun. 50, 275-287. doi: 10.1016/j.bbi.2015.07.018

Chang, P., Khatchadourian, A., McKinney, R., and Maysinger, D. (2015). Docosahexaenoic acid (DHA): a modulator of microglia activity and dendritic spine morphology. J. Neuroinflammation 12:34. doi: 10.1186/s12974-015-0244-5

Chen, C. T., Kitson, A. P., Hopperton, K. E., Domenichiello, A. F., Trépanier, M.O., Lin, L. E., et al. (2015). Plasma non-esterified docosahexaenoic acid is the major pool supplying the brain. Sci. Rep. 5:15791. doi: 10.1038/srep15791

Chen, X., Chen, C., Fan, S., Wu, S., Yang, F., Fang, Z., et al. (2018). Omega-3 polyunsaturated fatty acid attenuates the inflammatory response by modulating microglia polarization through SIRT1-mediated deacetylation of the HMGB1/NF- $\mathrm{B}$ pathway following experimental traumatic brain injury. J. Neuroinflammation 15:116. doi: 10.1186/s12974-018-1151-3

Curb, J. D., and Marcus, E. B. (1991). Body fat and obesity in Japanese Americans. Am. J. Clin. Nutr. 53, 1552S-1555S. doi: 10.1093/ajcn/53.6.1552S

Daniel, H., Gholami, A. M., Berry, D., Desmarchelier, C., Hahne, H., Loh, G., et al. (2014). High-fat diters gut microbiota physiology in mice. ISME J. 8, 295-308. doi: 10.1038/ismej.2013.155

Dantzer, R., O’Connor, J. C., Freund, G. G., Johnson, R. W., and Kelley, K. W. (2008). From inflammation to sickness and depression: when the immune system subjugates the brain. Nat. Rev. Neurosci. 9, 46-56. doi: 10.1038/nrn2297

David, L. A., Maurice, C. F., Carmody, R. N., Gootenberg, D. B., Button, J. E., Wolfe, B. E., et al. (2014). Diet rapidly and reproducibly alters the human gut microbiome. Nature 505, 559-563. doi: 10.1038/nature12820

Davis, J. E., Gabler, N. K., Walker-Daniels, J., and Spurlock, M. E. (2008). Tlr-4 deficiency selectively protects against obesity induced by diets high in saturated fat. Obesity 16, 1248-1255. doi: 10.1038/oby.2008.210

De Felice, F. G. (2013). Alzheimer's disease and insulin resistance: translating basic science into clinical applications. J. Clin. Invest. 123, 531-539. doi: 10.1172/ JCI64595

De Felice, F. G., and Ferreira, S. T. (2014). Inflammation, defective insulin signaling, and mitochondrial dysfunction as common molecular denominators connecting type 2 diabetes to Alzheimer disease. Diabetes 63, 2262-2272. doi: $10.2337 / \mathrm{db} 13-1954$

De Felice, F. G., Lourenco, M. V., and Ferreira, S. T. (2014). How does brain insulin resistance develop in Alzheimer's disease? Alzheimers Dement. 10, S26-S32. doi: 10.1016/j.jalz.2013.12.004

De Filippo, C., Cavalieri, D., Paola, M., Di, Ramazzotti, M., Poullet, J. B., et al. (2010). Impact of diet in shaping gut microbiota revealed by a comparative study in children from Europe and rural Africa. Proc. Natl. Acad. Sci. U.S.A. 107, 14691-14696. doi: 10.1073/PNAS.1005963107

De Smedt-Peyrusse, V., Sargueil, F., Moranis, A., Harizi, H., Mongrand, S., and Layé, S. (2008). Docosahexaenoic acid prevents lipopolysaccharide-induced cytokine production in microglial cells by inhibiting lipopolysaccharide receptor presentation but not its membrane subdomain localization. J. Neurochem. 105, 296-307. doi: 10.1111/j.1471-4159.2007.05129.x

DiNicolantonio, J. J., Mehta, V., Onkaramurthy, N., and O’Keefe, J. H. (2018). Fructose-induced inflammation and increased cortisol: a new mechanism for how sugar induces visceral adiposity. Prog. Cardiovasc. Dis. 61, 3-9. doi: 10. 1016/j.pcad.2017.12.001

Domenichiello, A. F., Chen, C. T., Trepanier, M.-O., Stavro, P. M., and Bazinet, R. P. (2014). Whole body synthesis rates of DHA from $\alpha$-linolenic acid are greater than brain DHA accretion and uptake rates in adult rats. J. Lipid Res. 55, 62-74. doi: 10.1194/jlr.M042275

Dresner, A., Laurent, D., Marcucci, M., Griffin, M. E., Dufour, S., Cline, G. W., et al. (1999). Effects of free fatty acids on glucose transport and IRS-1-associated phosphatidylinositol 3-kinase activity. J. Clin. Invest. 103, 253-259. doi: 10. 1172/JCI5001

Dutheil, S., Ota, K. T., Wohleb, E. S., Rasmussen, K., and Duman, R. S. (2016). High-fat diet induced anxiety and anhedonia: impact on brain homeostasis and inflammation. Neuropsychopharmacology 41, 1874-1887. doi: 10.1038/npp. 2015.357

Ebinuma, H., Miida, T., Yamauchi, T., Hada, Y., Hara, K., Kubota, N., et al. (2007). Improved ELISA for selective measurement of adiponectin multimers and identification of adiponectin in human cerebrospinal fluid. Clin. Chem. 53, 1541-1544. doi: 10.1373/clinchem.2007.085654

Eder, K., Baffy, N., Falus, A., and Fulop, A. K. (2009). The major inflammatory mediator interleukin-6 and obesity. Inflamm. Res. 58, 727-736. doi: 10.1007/ s00011-009-0060-4

Erny, D., Hrabě de Angelis, A. L., Jaitin, D., Wieghofer, P., Staszewski, O., David, E., et al. (2015). Host microbiota constantly control maturation and function of microglia in the CNS. Nat. Neurosci. 18, 965-977. doi: 10.1038/nn.4030

Erridge, C., and Samani, N. J. (2009). Saturated fatty acids do not directly stimulate toll-like receptor signaling. Arterioscler. Thromb. Vasc. Biol. 29, 1944-1949. doi: 10.1161/ATVBAHA.109.194050

Ferreira, S. T., Clarke, J. R., Bomfim, T. R., and De Felice, F. G. (2014). Inflammation, defective insulin signaling, and neuronal dysfunction in Alzheimer's disease. Alzheimers Dement. 10, S76-S83. doi: 10.1016/j.jalz.2013. 12.010

Fessler, M. B., Rudel, L. L., and Brown, J. M. (2009). Toll-like receptor signaling links dietary fatty acids to the metabolic syndrome. Curr. Opin. Lipidol. 20, 379-385. doi: 10.1097/MOL.0b013e32832fa5c4

Fordahl, S. C., and Jones, S. R. (2017). High-fat-diet-induced deficits in dopamine terminal function are reversed by restoring insulin signaling. ACS Chem. Neurosci. 8, 290-299. doi: 10.1021/acschemneuro.6b00308

Fung, T. C., Olson, C. A., and Hsiao, E. Y. (2017). Interactions between the microbiota, immune and nervous systems in health and disease. Nat. Neurosci. 20, 145-155. doi: 10.1038/nn.4476

Goodyear, L. J., Giorgino, F., Sherman, L. A., Carey, J., Smith, R. J., and Dohm, G. L. (1995). Insulin receptor phosphorylation, insulin receptor substrate-1 phosphorylation, and phosphatidylinositol 3-kinase activity are decreased in intact skeletal muscle strips from obese subjects. J. Clin. Invest. 95, 2195-2204. doi: 10.1172/JCI117909

Greenberg, A. S., and Obin, M. S. (2006). Obesity and the role of adipose tissue in inflammation and metabolism. Am. J. Clin. Nutr. 83, 461S-465S. doi: 10.1093/ ajcn/83.2.461S

Gu, M., Li, Y., Tang, H., Zhang, C., Li, W., Zhang, Y., et al. (2018). Endogenous omega (N)-3 fatty acids in fat-1 mice attenuated depression-like behavior, imbalance between microglial M1 and M2 phenotypes, and dysfunction of neurotrophins induced by lipopolysaccharide administration. Nutrients 10:E1351. doi: 10.3390/nu10101351

Gunaydin, L. A., Grosenick, L., Finkelstein, J. C., Kauvar, I. V., Fenno, L. E., Adhikari, A., et al. (2014). Natural neural projection dynamics underlying social behavior. Cell 157, 1535-1551. doi: 10.1016/j.cell.2014.05.017

Hachem, M., Géloën, A., Van, A. L., Foumaux, B., Fenart, L., Gosselet, F., et al. (2016). Efficient docosahexaenoic acid uptake by the brain from a structured phospholipid. Mol. Neurobiol. 53, 3205-3215. doi: 10.1007/s12035-015-9228-9

Hagnell, O. (1989). Repeated incidence and prevalence studies of mental disorders in a total population followed during 25 years The Lundby Study, Sweden. Acta Psychiatr. Scand. 79, 61-77. doi: 10.1111/j.1600-0447.1989.tb05216.x

Hamazaki, K., Hamazaki, T., and Inadera, H. (2012). Fatty acid composition in the postmortem amygdala of patients with schizophrenia, bipolar disorder, and major depressive disorder. J. Psychiatr. Res. 46, 1024-1028. doi: 10.1016/ J.JPSYCHIRES.2012.04.012

Hariri, N., and Thibault, L. (2010). High-fat diet-induced obesity in animal models. Nutr. Res. Rev. 23, 270-299. doi: 10.1017/S0954422410000168

Hassan, A. M., Mancano, G., Kashofer, K., Fröhlich, E. E., Matak, A., Mayerhofer, R., et al. (2018). High-fat diet induces depression-like behaviour in mice associated with changes in microbiome, neuropeptide $\mathrm{Y}$, and brain 
metabolome. Nutr. Neurosci. doi: 10.1080/1028415X.2018.1465713 [Epub ahead of print].

Heyward, F. D., Walton, R. G., Carle, M. S., Coleman, M. A., Garvey, W. T., and Sweatt, J. D. (2012). Adult mice maintained on a high-fat diet exhibit object location memory deficits and reduced hippocampal SIRT1 gene expression. Neurobiol. Learn. Mem. 98, 25-32. doi: 10.1016/J.NLM.2012.04.005

Hidaka, B. H. (2012). Depression as a disease of modernity: explanations for increasing prevalence. J. Affect. Disord. 140, 205-214. doi: 10.1016/j.jad.2011. 12.036

Hill, J. O., and Peters, J. C. (1998). Environmental contributions to the obesity epidemic. Science 280, 1371-1374. doi: 10.1126/SCIENCE.280.5368.1371

Hirosumi, J., Tuncman, G., Chang, L., Görgün, C. Z., Uysal, K. T., Maeda, K., et al. (2002). A central role for JNK in obesity and insulin resistance. Nature 420, 333-336. doi: 10.1038/nature01137

Holt, R. I. G., de Groot, M., and Golden, S. H. (2014). Diabetes and depression. Curr. Diab. Rep. 14:491. doi: 10.1007/s11892-014-0491-3

Horton, T. J., Drougas, H., Brachey, A., Reed, G. W., Peters, J. C., and Hill, J. O. (1995). Fat and carbohydrate overfeeding in humans: different effects on energy storage. Am. J. Clin. Nutr. 62, 19-29. doi: 10.1093/ajcn/62.1.19

Hotamisligil, G. S., Shargill, N. S., and Spiegelman, B. M. (1993). Adipose expression of tumor necrosis factor-alpha: direct role in obesity-linked insulin resistance. Science 259, 87-91.

Hotta, K., Funahashi, T., Arita, Y., Takahashi, M., Matsuda, M., Okamoto, Y., et al. (2000). Plasma concentrations of a novel, adipose-specific protein, adiponectin, in type 2 diabetic patients. Arterioscler. Thromb. Vasc. Biol. 20, 1595-1599.

Hu, S., Wang, L., Yang, D., Li, L., Togo, J., Wu, Y., et al. (2018). Dietary fat, but not protein or carbohydrate, regulates energy intake and causes adiposity in mice. Cell Metab. 28, 415-431.e4. doi: 10.1016/j.cmet.2018.06.010

Huang, S., Rutkowsky, J. M., Snodgrass, R. G., Ono-Moore, K. D., Schneider, D. A., Newman, J. W., et al. (2012). Saturated fatty acids activate TLR-mediated proinflammatory signaling pathways. J. Lipid Res. 53, 2002-2013. doi: 10.1194/ jlr.D029546

Innes, J. K., and Calder, P. C. (2018). Omega-6 fatty acids and inflammation. Prostaglandins Leukot. Essent. Fatty Acids 132, 41-48. doi: 10.1016/J.PLEFA. 2018.03.004

Jacka, F. N. (2017). Nutritional psychiatry: where to next? EBioMedicine 17, 24-29. doi: 10.1016/j.ebiom.2017.02.020

Jacka, F. N., Pasco, J. A., Mykletun, A., Williams, L. J., Hodge, A. M., O’Reilly, S. L., et al. (2010). Association of western and traditional diets with depression and anxiety in women. Am. J. Psychiatry 167, 305-311. doi: 10.1176/appi.ajp.2009. 09060881

Jeon, B. T., Jeong, E. A., Shin, H. J., Lee, Y., Lee, D. H., Kim, H. J., et al. (2012). Resveratrol attenuates obesity-associated peripheral and central inflammation and improves memory deficit in mice fed a high-fat diet. Diabetes 61, 14441454. doi: $10.2337 / \mathrm{db} 11-1498$

Kahn, R., and Sievenpiper, J. L. (2014). Dietary sugar and body weight: have we reached a crisis in the epidemic of obesity and diabetes? We have, but the pox on sugar is overwrought and overworked. Diabetes Care 37, 957-962. doi: $10.2337 / \mathrm{dc} 13-2506$

Kalmijn, S., Launer, L. J., Ott, A., Witteman, J. C. M., Hofman, A., and Breteler, M. M. B. (1997). Dietary fat intake and the risk of incident dementia in the Rotterdam study. Ann. Neurol. 42, 776-782. doi: 10.1002/ana.410420514

Kelly, J. R., Borre, Y., O’ Brien, C., Patterson, E., El Aidy, S., Deane, J., et al. (2016). Transferring the blues: depression-associated gut microbiota induces neurobehavioural changes in the rat. J. Psychiatr. Res. 82, 109-118. doi: 10.1016/ j.jpsychires.2016.07.019

Khan, T. A., and Sievenpiper, J. L. (2016). Controversies about sugars: results from systematic reviews and meta-analyses on obesity, cardiometabolic disease and diabetes. Eur. J. Nutr. 55, 25-43. doi: 10.1007/s00394-0161345-3

Kim, H.-W., Rapoport, S. I., and Rao, J. S. (2009). Altered arachidonic acid cascade enzymes in postmortem brain from bipolar disorder patients. Mol. Psychiatry 16, 419-428. doi: 10.1038/mp.2009.137

Kleinert, M., Clemmensen, C., Hofmann, S. M., Moore, M. C., Renner, S., Woods, S. C., et al. (2018). Animal models of obesity and diabetes mellitus. Nat. Rev. Endocrinol. 14, 140-162. doi: 10.1038/nrendo.2017.161

Kleinridders, A., Cai, W., Cappellucci, L., Ghazarian, A., Collins, W. R., Vienberg, S. G., et al. (2015). Insulin resistance in brain alters dopamine turnover and causes behavioral disorders. Proc. Natl. Acad. Sci. U.S.A. 112, 3463-3468. doi: 10.1073/pnas.1500877112

Kopelman, P. G. (2000). Obesity as a medical problem. Nature 404, 635-643. doi: $10.1038 / 35007508$

Kreutzberg, G. W. (1996). Microglia: a sensor for pathological events in the CNS. Trends Neurosci. 19, 312-318. doi: 10.1016/0166-2236(96)10049-7

Krishnan, V., and Nestler, E. J. (2011). Animal models of depression: molecular perspectives. Curr. Top. Behav. Neurosci. 7, 121-147. doi: 10.1007/7854_2010_108

Lai, J. S., Hiles, S., Bisquera, A., Hure, A. J., McEvoy, M., and Attia, J. (2014). A systematic review and meta-analysis of dietary patterns and depression in community-dwelling adults. Am. J. Clin. Nutr. 99, 181-197. doi: 10.3945/ajcn. 113.069880

Laitinen, M. H., Ngandu, T., Rovio, S., Helkala, E.-L., Uusitalo, U., Viitanen, M., et al. (2006). Fat intake at midlife and risk of dementia and Alzheimer's disease: a population-based study. Dement. Geriatr. Cogn. Disord. 22, 99-107. doi: 10. $1159 / 000093478$

Lancaster, G. I., Langley, K. G., Berglund, N. A., Kammoun, H. L., Reibe, S., Estevez, E., et al. (2018). Evidence that TLR4 is not a receptor for saturated fatty acids but mediates lipid-induced inflammation by reprogramming macrophage metabolism. Cell Metab. 27, 1096-1110.e5. doi: 10.1016/j.cmet.2018.03.014

Lauritzen, L., Hansen, H., Jørgensen, M., and Michaelsen, K. (2001). The essentiality of long chain $\mathrm{n}-3$ fatty acids in relation to development and function of the brain and retina. Prog. Lipid Res. 40, 1-94. doi: 10.1016/S0163-7827(00) 00017-5

Lawton, C. L., Delargy, H. J., Brockman, J., Smith, F. C., and Blundell, J. E. (2000). The degree of saturation of fatty acids influences post-ingestive satiety. $\mathrm{Br}$. J. Nutr. 83, 473-482.

Lê, K.-A., Ith, M., Kreis, R., Faeh, D., Bortolotti, M., Tran, C., et al. (2009). Fructose overconsumption causes dyslipidemia and ectopic lipid deposition in healthy subjects with and without a family history of type 2 diabetes. Am. J. Clin. Nutr. 89, 1760-1765. doi: 10.3945/ajcn.2008.27336

Lee, J. Y., Sohn, K. H., Rhee, S. H., and Hwang, D. (2001). Saturated fatty acids, but not unsaturated fatty acids, induce the expression of cyclooxygenase2 mediated through toll-like receptor 4. J. Biol. Chem. 276, 16683-16689. doi: $10.1074 /$ jbc.M011695200

Lee, Y. S., Li, P., Huh, J. Y., Hwang, I. J., Lu, M., Kim, J. I., et al. (2011). Inflammation is necessary for long-term but not short-term high-fat dietinduced insulin resistance. Diabetes 60, 2474-2483. doi: 10.2337/db11-0194

Lin, P.-Y., Huang, S.-Y., and Su, K.-P. (2010). A meta-analytic review of polyunsaturated fatty acid compositions in patients with depression. Biol. Psychiatry 68, 140-147. doi: 10.1016/j.biopsych.2010.03.018

Liu, J., Guo, M., Zhang, D., Cheng, S.-Y., Liu, M., Ding, J., et al. (2012). Adiponectin is critical in determining susceptibility to depressive behaviors and has antidepressant-like activity. Proc. Natl. Acad. Sci. U.S.A. 109, 12248-12253. doi: 10.1073/pnas.1202835109

Liu, J. J., Green, P., John Mann, J., Rapoport, S. I., and Sublette, M. E. (2015). Pathways of polyunsaturated fatty acid utilization: implications for brain function in neuropsychiatric health and disease. Brain Res. 1597, 220-246. doi: 10.1016/j.brainres.2014.11.059

Liuzzi, G. M., Latronico, T., Rossano, R., Viggiani, S., Fasano, A., and Riccio, P. (2007). Inhibitory effect of polyunsaturated fatty acids on MMP-9 release from microglial cells-implications for complementary multiple sclerosis treatment. Neurochem. Res. 32, 2184-2193. doi: 10.1007/s11064-007-9415-9

Logan, A. C., and Jacka, F. N. (2014). Nutritional psychiatry research: an emerging discipline and its intersection with global urbanization, environmental challenges and the evolutionary mismatch. J. Physiol. Anthropol. 33:22. doi: 10.1186/1880-6805-33-22

Lu, Y.-C., Yeh, W.-C., and Ohashi, P. S. (2008). LPS/TLR4 signal transduction pathway. Cytokine 42, 145-151. doi: 10.1016/J.CYTO.2008.01.006

Luchsinger, J. A. (2012). Type 2 diabetes and cognitive impairment: linking mechanisms. J. Alzheimers Dis. 30, S185-S198. doi: 10.3233/JAD-2012-111433

Ludwig, D. S., Peterson, K. E., and Gortmaker, S. L. (2001). Relation between consumption of sugar-sweetened drinks and childhood obesity: a prospective, observational analysis. Lancet 357, 505-508. doi: 10.1016/S0140-6736(00) 04041- 1

Ludwig, D. S., Willett, W. C., Volek, J. S., and Neuhouser, M. L. (2018). Dietary fat: from foe to friend? Science 770, 764-770. doi: 10.1126/science.aau2096 
Lumeng, C. N., Bodzin, J. L., and Saltiel, A. R. (2007). Obesity induces a phenotypic switch in adipose tissue macrophage polarization. J. Clin. Invest. 117, 175-184. doi: 10.1172/JCI29881

Malik, V. S., Popkin, B. M., Bray, G. A., Després, J.-P., Willett, W. C., and Hu, F. B. (2010). Sugar-sweetened beverages and risk of metabolic syndrome and type 2 diabetes: a meta-analysis. Diabetes Care 33, 2477-2483. doi: 10.2337/dc10-1079

Malik, V. S., Schulze, M. B., and Hu, F. B. (2006). Intake of sugar-sweetened beverages and weight gain: a systematic review. Am. J. Clin. Nutr. 84, 274-288. doi: $10.1093 /$ ajen/84.2.274

Matcovitch-Natan, O., Winter, D. R., Giladi, A., Vargas Aguilar, S., Spinrad, A., Sarrazin, S., et al. (2016). Microglia development follows a stepwise program to regulate brain homeostasis. Science 353:aad8670. doi: 10.1126/science.aad8670

Matthews, G. A., Nieh, E. H., Vander Weele, C. M., Halbert, S. A., Pradhan, R. V., Yosafat, A. S., et al. (2016). Dorsal raphe dopamine neurons represent the experience of social isolation. Cell 164, 617-631. doi: 10.1016/j.cell.2015.12.040

McNamara, R. K., Hahn, C.-G., Jandacek, R., Rider, T., Tso, P., Stanford, K. E., et al. (2007). Selective deficits in the omega-3 fatty acid docosahexaenoic acid in the postmortem orbitofrontal cortex of patients with major depressive disorder. Biol. Psychiatry 62, 17-24. doi: 10.1016/j.biopsych.2006.08.026

McNamara, R. K., Jandacek, R., Tso, P., Dwivedi, Y., Ren, X., and Pandey, G. N. (2013). Lower docosahexaenoic acid concentrations in the postmortem prefrontal cortex of adult depressed suicide victims compared with controls without cardiovascular disease. J. Psychiatr. Res. 47, 1187-1191. doi: 10.1016/ j.jpsychires.2013.05.007

Mechawar, N., and Savitz, J. (2016). Neuropathology of mood disorders: do we see the stigmata of inflammation? Transl. Psychiatry 6:e946. doi: $10.1038 /$ tp.2016.212

Mock, K., Lateef, S., Benedito, V. A., and Tou, J. C. (2017). High-fructose corn syrup-55 consumption alters hepatic lipid metabolism and promotes triglyceride accumulation. J. Nutr. Biochem. 39, 32-39. doi: 10.1016/J. JNUTBIO.2016.09.010

Mocking, R. J. T., Harmsen, I., Assies, J., Koeter, M. W. J., Ruhé, H. G., and Schene, A. H. (2016). Meta-analysis and meta-regression of omega-3 polyunsaturated fatty acid supplementation for major depressive disorder. Transl. Psychiatry 6:e756. doi: 10.1038/tp.2016.29

Montonen, J., Järvinen, R., Knekt, P., Heliövaara, M., and Reunanen, A. (2007). Consumption of sweetened beverages and intakes of fructose and glucose predict type 2 diabetes occurrence. J. Nutr. 137, 1447-1454. doi: 10.1093/jn/ 137.6.1447

Morris, M. C., Evans, D. A., Bienias, J. L., Tangney, C. C., Bennett, D. A., Aggarwal, N., et al. (2003a). Dietary fats and the risk of incident Alzheimer disease. Arch. Neurol. 60, 194-200.

Morris, M. C., Evans, D. A., Bienias, J. L., Tangney, C. C., Bennett, D. A., Wilson, R. S., et al. (2003b). Consumption of fish and n-3 fatty acids and risk of incident Alzheimer disease. Arch. Neurol. 60, 940-946. doi: 10.1001/archneur.60.7.940

Morris, M. C., Evans, D. A., Bienias, J. L., Tangney, C. C., and Wilson, R. S. (2004). Dietary fat intake and 6-year cognitive change in an older biracial community population. Neurology 62, 1573-1579. doi: 10.1212/01. WNL.0000123250.82849.B6

Mosca, A., Nobili, V., De Vito, R., Crudele, A., Scorletti, E., Villani, A., et al. (2017). Serum uric acid concentrations and fructose consumption are independently associated with NASH in children and adolescents. J. Hepatol. 66, 1031-1036. doi: 10.1016/j.jhep.2016.12.025

Moussavi, N., Gavino, V., and Receveur, O. (2008). Could the quality of dietary fat, and not just its quantity, be related to risk of obesity? Obesity 16, 7-15. doi: 10.1038/oby.2007.14

Müller, N., and Schwarz, M. J. (2007). The immune-mediated alteration of serotonin and glutamate: towards an integrated view of depression. Mol. Psychiatry 12, 988-1000. doi: 10.1038/sj.mp.4002006

Nguyen, L. N., Ma, D., Shui, G., Wong, P., Cazenave-Gassiot, A., Zhang, X., et al. (2014). MFSD2A is a transporter for the essential omega-3 fatty acid docosahexaenoic acid. Nature 509, 503-506. doi: 10.1038/nature13241

O'Connor, J. C., André, C., Wang, Y., Lawson, M. A., Szegedi, S. S., Lestage, J., et al. (2009). Interferon-gamma and tumor necrosis factor-alpha mediate the upregulation of indoleamine 2,3-dioxygenase and the induction of depressivelike behavior in mice in response to bacillus Calmette-Guerin. J. Neurosci. 29, 4200-4209. doi: 10.1523/JNEUROSCI.5032-08.2009
O’Neil, A., Quirk, S. E., Housden, S., Brennan, S. L., Williams, L. J., Pasco, J. A., et al. (2014). Relationship between diet and mental health in children and adolescents: a systematic review. Am. J. Public Health 104, e31-e42. doi: 10. 2105/AJPH.2014.302110

Ortega, R. M., Requejo, A. M., Andrés, P., López-Sobaler, A. M., Quintas, M. E., Redondo, M. R., et al. (1997). Dietary intake and cognitive function in a group of elderly people. Am. J. Clin. Nutr. 66, 803-809. doi: 10.1093/ajcn/66.4.803

Ott, A., Stolk, R. P., Hofman, A., Van Harskamp, F., Grobbee, D. E., and Breteler, M. M. B. (1996). Association of diabetes mellitus and dementia: the Rotterdam study. Diabetologia 39, 1392-1397. doi: 10.1007/s001250050588

Ouchi, N., and Walsh, K. (2007). Adiponectin as an anti-inflammatory factor. Clin. Chim. Acta 380, 24-30. doi: 10.1016/j.cca.2007.01.026

Ouyang, X., Cirillo, P., Sautin, Y., McCall, S., Bruchette, J. L., Diehl, A. M., et al. (2008). Fructose consumption as a risk factor for non-alcoholic fatty liver disease. J. Hepatol. 48, 993-999. doi: 10.1016/j.jhep.2008.02.011

Pal, D., Dasgupta, S., Kundu, R., Maitra, S., Das, G., Mukhopadhyay, S., et al. (2012). Fetuin-A acts as an endogenous ligand of TLR4 to promote lipidinduced insulin resistance. Nat. Med. 18, 1279-1285. doi: 10.1038/nm.2851

Pan, Y., Scanlon, M. J., Owada, Y., Yamamoto, Y., Porter, C. J. H., and Nicolazzo, J. A. (2015). Fatty acid-binding protein 5 facilitates the blood-brain barrier transport of docosahexaenoic acid. Mol. Pharm. 12, 4375-4385. doi: 10.1021/ acs.molpharmaceut.5b00580

Pan, Y., Short, J. L., Choy, K. H. C., Zeng, A. X., Marriott, P. J., Owada, Y., et al. (2016). Fatty acid-binding protein 5 at the blood-brain barrier regulates endogenous brain docosahexaenoic acid levels and cognitive function. J. Neurosci. 36, 11755-11767. doi: 10.1523/JNEUROSCI.1583-16.2016

Paolicelli, R. C., Bolasco, G., Pagani, F., Maggi, L., Scianni, M., Panzanelli, P., et al. (2011). Synaptic pruning by microglia is necessary for normal brain development. Science 333, 1456-1458. doi: 10.1126/science.1202529

Park, B. S., Song, D. H., Kim, H. M., Choi, B.-S., Lee, H., and Lee, J.-O. (2009). The structural basis of lipopolysaccharide recognition by the TLR4-MD-2 complex. Nature 458, 1191-1195. doi: 10.1038/nature07830

Phillips, C. M., Kesse-Guyot, E., McManus, R., Hercberg, S., Lairon, D., Planells, R., et al. (2012). High dietary saturated fat intake accentuates obesity risk associated with the fat mass and obesity-associated gene in adults. J. Nutr. 142, 824-831. doi: $10.3945 /$ jn.111.153460

Piers, L. S., Walker, K. Z., Stoney, R. M., Soares, M. J., and O’Dea, K. (2003). Substitution of saturated with monounsaturated fat in a 4 -week diet affects body weight and composition of overweight and obese men. Br. J. Nutr. 90, 717-727. doi: 10.1079/BJN2003948

Poggi, M., Bastelica, D., Gual, P., Iglesias, M. A., Gremeaux, T., Knauf, C., et al. (2007). C3H/HeJ mice carrying a toll-like receptor 4 mutation are protected against the development of insulin resistance in white adipose tissue in response to a high-fat diet. Diabetologia 50, 1267-1276. doi: 10.1007/s00125-007-0654-8

Popkin, B. M., Adair, L. S., and Ng, S. W. (2012). Global nutrition transition and the pandemic of obesity in developing countries. Nutr. Rev. 70, 3-21. doi: 10.1111/j.1753-4887.2011.00456.x

Popkin, B. M., and Gordon-Larsen, P. (2004). The nutrition transition: worldwide obesity dynamics and their determinants. Int. J. Obes. 28, 2-9. doi: 10.1038/sj. ijo.0802804

Psaltopoulou, T., Sergentanis, T. N., Panagiotakos, D. B., Sergentanis, I. N., Kosti, R., and Scarmeas, N. (2013). Mediterranean diet, stroke, cognitive impairment, and depression: a meta-analysis. Ann. Neurol. 74, 580-591. doi: 10.1002/ana.23944

Rebolledo-Solleiro, D., Roldán-Roldán, G., Díaz, D., Velasco, M., Larqué, C., RicoRosillo, G., et al. (2017). Increased anxiety-like behavior is associated with the metabolic syndrome in non-stressed rats. PLoS One 12:e0176554. doi: 10.1371/ journal.pone. 0176554

Reichelt, A. C., Westbrook, R. F., and Morris, M. J. (2017). Editorial: impact of diet on learning, memory and cognition. Front. Behav. Neurosci. 11:96. doi: 10.3389/fnbeh.2017.00096

Rey, C., Nadjar, A., Buaud, B., Vaysse, C., Aubert, A., Pallet, V., et al. (2016). Resolvin D1 and E1 promote resolution of inflammation in microglial cells in vitro. Brain Behav. Immun. 55, 249-259. doi: 10.1016/J.BBI.2015.12.013

Roden, M., Price, T. B., Perseghin, G., Petersen, K. F., Rothman, D. L., Cline, G. W., et al. (1996). Mechanism of free fatty acid-induced insulin resistance in humans. J. Clin. Invest. 97, 2859-2865. doi: 10.1172/JCI118742 
Rogero, M. M., and Calder, P. C. (2018). Obesity, inflammation, toll-like receptor 4 and fatty acids. Nutrients 10:E432. doi: 10.3390/nu10040432

Rosqvist, F., Iggman, D., Kullberg, J., Cedernaes, J., Johansson, H. E., Larsson, A., et al. (2014). Overfeeding polyunsaturated and saturated fat causes distinct effects on liver and visceral fat accumulation in humans. Diabetes 63, 2356-2368. doi: 10.2337/db13-1622

Ruhé, H. G., Mason, N. S., and Schene, A. H. (2007). Mood is indirectly related to serotonin, norepinephrine and dopamine levels in humans: a meta-analysis of monoamine depletion studies. Mol. Psychiatry 12, 331-359. doi: 10.1038/sj.mp. 4001949

Santos, L. E., Beckman, D., and Ferreira, S. T. (2016). Microglial dysfunction connects depression and Alzheimer's disease. Brain Behav. Immun. 55, 151-165. doi: 10.1016/j.bbi.2015.11.011

Scarmeas, N., Stern, Y., Tang, M.-X., Mayeux, R., and Luchsinger, J. A. (2006). Mediterranean diet and risk for Alzheimer's disease. Ann. Neurol. 59, 912-921. doi: 10.1002/ana.20854

Sevilla-González, M., del, R., Quintana-Mendoza, B. M., and Aguilar-Salinas, C. A. (2017). Interaction between depression, obesity, and type 2 diabetes: a complex picture. Arch. Med. Res. 48, 582-591. doi: 10.1016/j.arcmed.2018.02.004

Sheline, Y. I. (2011). Depression and the hippocampus: cause or effect? Biol. Psychiatry 70, 308-309. doi: 10.1016/j.biopsych.2011.06.006

Shi, H., Kokoeva, M. V., Inouye, K., Tzameli, I., Yin, H., and Flier, J. S. (2006). TLR4 links innate immunity and fatty acid-induced insulin resistance. J. Clin. Invest. 116, 3015-3025. doi: 10.1172/JCI28898

Simopoulos, A. P. (2011). Evolutionary aspects of diet: the omega-6/omega-3 ratio and the brain. Mol. Neurobiol. 44, 203-215. doi: 10.1007/s12035-010-8162-0

Singh, A., and Abraham, W. C. (2017). Astrocytes and synaptic plasticity in health and disease. Exp. Brain Res. 235, 1645-1655. doi: 10.1007/s00221-017-4928-1

Sinyor, M., Schaffer, A., and Levitt, A. (2010). The sequenced treatment alternatives to relieve depression (STAR*D) trial: a review. Can. J. Psychiatry 55, 126-135. doi: $10.1177 / 070674371005500303$

Spiegelman, B. M., and Flier, J. S. (2001). Obesity and the regulation review of energy balance. Cell 104, 531-543.

Stanhope, K. L. (2016). Sugar consumption, metabolic disease and obesity: the state of the controversy. Crit. Rev. Clin. Lab. Sci. 53, 52-67. doi: 10.3109/10408363. 2015.1084990

Stanhope, K. L., Schwarz, J. M., Keim, N. L., Griffen, S. C., Bremer, A. A., Graham, J. L., et al. (2009). Consuming fructose-sweetened, not glucose-sweetened, beverages increases visceral adiposity and lipids and decreases insulin sensitivity in overweight/obese humans. J. Clin. Invest. 119, 1322-1334. doi: 10.1172/ JCI37385

Sun, K., Kusminski, C. M., and Scherer, P. E. (2011). Adipose tissue remodeling and obesity. J. Clin. Invest. 121, 2094-2101. doi: 10.1172/JCI45887

Swardfager, W., Rosenblat, J. D., Benlamri, M., and McIntyre, R. S. (2016). Mapping inflammation onto mood: inflammatory mediators of anhedonia. Neurosci. Biobehav. Rev. 64, 148-166. doi: 10.1016/j.neubiorev.2016.02.017

Tye, K. M., Mirzabekov, J. J., Warden, M. R., Ferenczi, E. A., Tsai, H.-C., Finkelstein, J., et al. (2012). Dopamine neurons modulate neural encoding and expression of depression-related behaviour. Nature 493, 537-541. doi: 10.1038/ nature 11740

Umhau, J. C., Zhou, W., Carson, R. E., Rapoport, S. I., Polozova, A., Demar, J., et al. (2009). Imaging incorporation of circulating docosahexaenoic acid into the human brain using positron emission tomography. J. Lipid Res. 50, 1259-1268. doi: 10.1194/jlr.M800530-JLR200

Vagena, E., Ryu, J. K., Baeza-Raja, B., Walsh, N. M., Syme, C., Day, J. P., et al. (2018). A high-fat diet promotes depression-like behavior in mice by suppressing hypothalamic PKA signaling. SSRN Electron. J. doi: 10.2139/ssrn.3188483

Valdearcos, M., Robblee, M. M., Benjamin, D. I., Nomura, D. K., Xu, A. W., and Koliwad, S. K. (2014). Microglia dictate the impact of saturated fat consumption on hypothalamic inflammation and neuronal function. Cell Rep. 9, 2124-2138. doi: 10.1016/j.celrep.2014.11.018

van Dijk, S. J., Feskens, E. J. M., Bos, M. B., Hoelen, D. W. M., Heijligenberg, R., Bromhaar, M. G., et al. (2009). A saturated fatty acid-rich diet induces an obesity-linked proinflammatory gene expression profile in adipose tissue of subjects at risk of metabolic syndrome. Am. J. Clin. Nutr. 90, 1656-1664. doi: 10.3945/ajcn.2009.27792.INTRODUCTION

Vergnaud, A.-C., Norat, T., Mouw, T., Romaguera, D., May, A. M., Bueno-de-Mesquita, H. B., et al. (2013). Macronutrient composition of the diet and prospective weight change in participants of the EPIC-PANACEA study. PLoS One 8:e57300. doi: 10.1371/journal.pone.0057300

Vessby, B., Uusitupa, M., Hermansen, K., Riccardi, G., Rivellese, A. A., Tapsell, L. C., et al. (2001). Substituting dietary saturated for monounsaturated fat impairs insulin sensitivity in healthy men and women: the KANWU study. Diabetologia 44, 312-319. doi: 10.1007/s001250051620

Wang, H., Zhou, J., Liu, Q. Z., Wang, L. L., and Shang, J. (2017). Simvastatin and bezafibrate ameliorate emotional disorder induced by high fat diet in C57BL/6 mice. Sci. Rep. 7:2335. doi: 10.1038/s41598-017-02576-5

Wang, Z., Liu, D., Wang, F., Liu, S., Zhao, S., Ling, E. A., et al. (2012). Saturated fatty acids activate microglia via Toll-like receptor $4 / \mathrm{NF}-\kappa \mathrm{B}$ signalling. $\mathrm{Br} . J$. Nutr. 107, 229-241. doi: 10.1017/S0007114511002868

Wellen, K. E., and Hotamisligil, G. S. (2003). Obesity-induced inflammatory changes in adipose tissue. J. Clin. Invest. 112, 1785-1788. doi: 10.1172/JCI20514

Wichers, M. C., and Maes, M. (2004). The role of indoleamine 2,3-dioxygenase (IDO) in the pathophysiology of interferon-alpha-induced depression. J. Psychiatry Neurosci. 29, 11-17.

Willett, W. C. (1998). Is dietary fat a major determinant of body fat? Am. J. Clin. Nutr. 67, 556S-562S. doi: 10.1093/ajcn/67.3.556S

Willett, W. C. (2002). Dietary fat plays a major role in obesity: no. Obes. Rev. 3 , 59-68. doi: 10.1046/j.1467-789X.2002.00060.x

Xu, H., Barnes, G. T., Yang, Q., Tan, G., Yang, D., Chou, C. J., et al. (2003). Chronic inflammation in fat plays a crucial role in the development of obesity-related insulin resistance. J. Clin. Invest. 112, 1821-1830. doi: 10.1172/JCI19451

Xu, L., Xu, S., Lin, L., Gu, X., Fu, C., Fang, Y., et al. (2018). High-fat diet mediates anxiolytic-like behaviors in a time-dependent manner through the regulation of SIRT1 in the brain. Neuroscience 372, 237-245. doi: 10.1016/j.neuroscience. 2018.01.001

Yang, J. L., Liu, D. X., Jiang, H., Pan, F., Ho, C. S., and Ho, R. C. M. (2016). The effects of high-fat-diet combined with chronic unpredictable mild stress on depression-like behavior and leptin/LepRb in male rats. Sci. Rep. 6:35239. doi: 10.1038/srep35239

Yang, W.-S., Lee, W.-J., Funahashi, T., Tanaka, S., Matsuzawa, Y., Chao, C.-L., et al. (2002). Plasma adiponectin levels in overweight and obese Asians. Obes. Res. 10, 1104-1110. doi: 10.1038/oby.2002.150

Yanguas-Casás, N., Crespo-Castrillo, A., de Ceballos, M. L., Chowen, J. A., Azcoitia, I., Arevalo, M. A., et al. (2018). Sex differences in the phagocytic and migratory activity of microglia and their impairment by palmitic acid. Glia 66 , 522-537. doi: $10.1002 /$ glia.23263

Yehuda, S., Rabinovitz, S., and Mostofsky, D. I. (1999). Essential fatty acids are mediators of brain biochemistry and cognitive functions. J. Neurosci. Res. 56, 565-570. doi: 10.1002/(SICI)1097-4547(19990615)56:6<565::AID-JNR2>3. $0 . \mathrm{CO} ; 2-\mathrm{H}$

Yirmiya, R., Rimmerman, N., and Reshef, R. (2015). Depression as a microglial disease. Trends Neurosci. 38, 637-658. doi: 10.1016/j.tins.2015.08.001

Yuan, M., Konstantopoulos, N., Lee, J., Hansen, L., Li, Z. W., Karin, M., et al. (2001). Reversal of obesity- and diet-induced insulin resistance with salicylates or targeted disruption of Ikkbeta. Science 293, 1673-1677. doi: 10.1126/science. 1061620

Zárate, R., El Jaber-Vazdekis, N., Tejera, N., Pérez, J. A., and Rodríguez, C. (2017). Significance of long chain polyunsaturated fatty acids in human health. Clin. Transl. Med. 6:25. doi: 10.1186/s40169-017-0153-6

Zheng, P., Zeng, B., Zhou, C., Liu, M., Fang, Z., Xu, X., et al. (2016). Gut microbiome remodeling induces depressive-like behaviors through a pathway mediated by the host's metabolism. Mol. Psychiatry 21, 786-796. doi: 10.1038/ mp.2016.44

Conflict of Interest Statement: The authors declare that the research was conducted in the absence of any commercial or financial relationships that could be construed as a potential conflict of interest.

Copyright (c) 2019 Melo, Santos and Ferreira. This is an open-access article distributed under the terms of the Creative Commons Attribution License (CC BY). The use, distribution or reproduction in other forums is permitted, provided the original author(s) and the copyright owner(s) are credited and that the original publication in this journal is cited, in accordance with accepted academic practice. No use, distribution or reproduction is permitted which does not comply with these terms. 